\title{
Cost-Effectiveness of Insulin Glargine and Insulin Detemir in the Basal Regimen for Naïve Insulin Patients with Type 2 Diabetes Mellitus (T2DM) in Malaysia
}

\author{
Asrul Akmal Shafie $\mathbb{D}^{1}$ \\ Chin Hui $\mathrm{Ng}^{2}$ \\ 'Discipline of Social and Administrative \\ Pharmacy, School of Pharmaceutical \\ Sciences, Penang, Malaysia; ${ }^{2}$ Pharmacy \\ Department, Hospital Raja Permaisuri \\ Bainun, Ipoh 30450, Perak, Malaysia
}

This article was published in the following Dove Press journal:

ClinicoEconomics and Outcomes Research

\begin{abstract}
Objective: To compare the cost-effectiveness of long-acting insulin analogue (LAIA) (insulin Detemir and insulin Glargine) versus NPH insulin in the basal insulin regime for naïve insulin T2DM Malaysian patients.

Methods: The UKPDS-Outcome Model version 2.0 (UKPDS-OM2) was used to evaluate the cost and consequence of diabetes-related complication. The effectiveness of the insulin was derived from the literature review, and the patients' epidemiology characteristics were retrieved from the Malaysian Diabetes Registry. A discount rate of 3\% was applied to both costs and health effects. Another simple mathematical model was used to compare the benefit of reducing the hypoglycemia events between LAIA and NPH insulin. The outputs of the models were combined to obtain the final result. One-way sensitivity analyses were performed to assess the uncertainties.

Results: The net cost difference (without accounting for hypoglycemia) was RM4868 for insulin Glargine and RM6026 for insulin Detemir. The saving from preventing severe hypoglycemia was RM4377 for insulin Glargine and RM12,753 for insulin Detemir. The total additional QALY gained from insulin Glargine was 0.1317 and from insulin Detemir was 0.8376 . The sensitivity analysis shows the discount rate, and drug acquisition cost may affect the incremental cost-effectiveness ratio (ICER) value.

Conclusion: Both insulin Detemir and Glargine are cost-effective compared to NPH insulin for T2DM patients, especially when the benefit of reducing the hypoglycemia event rate is taken into account.
\end{abstract}

Keywords: type 2 diabetes mellitus, insulin Glargine, insulin Detemir, cost-effectiveness analysis

\section{Introduction}

Malaysia has one of the highest Type 2 diabetes rates in the world, and in Asia, Malaysia ranks second behind Saudi Arabia, with an estimated that more than a third of adults over 30 years old will have developed diabetes by $2020 .^{1}$ The prevalence of Type 2 Diabetes Mellitus (T2DM) in the Malaysian population increased from $14.9 \%$ in 2006 to $20.8 \%$ (approximately 2.8 million individuals) in 2011, with deteriorating glycemic control, and a rising mean of hemoglobin A1c (HbA1c) from $8.00 \%$ to $8.66 \% .^{2}$ Uncontrolled glycemic goals may lead to acute life-threatening metabolic complications and will increase the risks of morbidity
Correspondence: Asrul Akmal Shafie Discipline of Social and Administrative Pharmacy, School of Pharmaceutical Sciences, I 800 Universiti Sains Malaysia, Penang, Malaysia

Email aakmal@usm.my 
and mortality due to the potential of leading to the development of diabetic-related complications. The Ministry of Health Malaysia recorded 23,800 deaths caused by diabetes. Ten percent of T2DM patients were found to have serum creatine values higher than $2 \mathrm{mg} / \mathrm{dl},{ }^{2}$ a common sign of acute renal failure. In the same literature, nearly half $(11.5 \%)$ of T2DM patients who underwent albuminuria tests have microalbuminuria or macroalbuminuria condition and the prevalence of combined microvascular complications was $75 \%$ and macrovascular complication was $29 \%{ }^{2}$

The overall aim in the management of diabetes is to prevent the appearance of disease-related complications, decrease mortality, and improve quality of life. In a landmark study, the UK Prospective Diabetes Study (UKPDS) revealed a $25 \%$ and $16 \%$ reduction of microvascular complications and myocardial infarction respectively among patients with controlled blood glucose. ${ }^{3}$ Consequently, insulin therapy is recommended for patients with T2DM especially patients with HbAlc values greater than $9 \%,{ }^{4}$ with basal insulin-like intermediate-acting insulin (eg, NPH insulin) commonly employed in intensive treatment. ${ }^{3}$ This intensive treatment helped to decrease the median of HbAlc by $1.7 \%$ to a stable level of $6.4 \%$ within a year and reduced the overall risk of the primary outcome of non-fatal myocardial infarction, non-fatal stroke, and cardiovascular death by $10 \% .{ }^{5}$ However, insulin treatment increases the risk of hypoglycemia episodes, meaning physicians and patients have to find a balance between the attainment of good glycemic control and hypoglycemic risks. Symptoms of hypoglycemia of any severity have a profound impact on patients as they are barriers to achieving normoglycemia.

Long-acting insulin analogues (LAIA), for instance, insulin Glargine and insulin Detemir overcome the pharmacokinetic shortcoming of NPH insulin using genetic modification in the amino acid sequence of the insulin molecule. ${ }^{4}$ Thus, it is possible to maintain the basal level of insulin and remain peak-less compared to intermediate-acting human insulin, ${ }^{6}$ and consistently show an improvement between glycemic control and tolerability in comparison to NPH insulin. LAIA has significantly reduced symptomatic hypoglycemia and nocturnal hypoglycemia risks (by at least $21 \%$ and $50 \%$, respectively) compared to NPH insulin. ${ }^{7,8}$ One study has found that the rates of overnight hypoglycemia were much lower in T2DM patients on LAIA compared to patients commonly on NPH insulin, and a significantly lower weight gain was recorded for patients using insulin Detemir. $^{8}$

Compared to Australia, utilization of insulin in Malaysia is relatively low ${ }^{9}$ where commonly used premixed insulin and fast-acting insulin analogues insulin were 3.71 defined daily doses (DDDs)/1000 population/ day in 2008. ${ }^{9}$ As T2DM patients fail to achieve their glycemic goals, insulin therapy is unavoidable because basal insulin is recommended as adjuvant therapy for patients who are already taking two types of oral hyperglycemic drugs. Thus basal insulin, either NPH insulin or LAIA, ${ }^{10}$ helps to maintain stable blood glucose levels during fasting and nocturnal periods. LAIA effectively improves and maintains glycemic control, demonstrating a lower risk of nocturnal hypoglycemia when compared with NPH insulin. ${ }^{11}$

The main reason for the low utilization of insulin in Malaysia is patients' refusal to use insulin therapy $(74.2 \%$ of respondents in a survey) for fear of unwarranted hypoglycemic events. ${ }^{12}$ Health care resources are limited; therefore, decision-makers need economic evaluation analysis as a tool to determine the need for introducing LAIA to T2DM patients. The objective of this study is to evaluate the cost-effectiveness of LAIA versus NPH insulin as insulin basal among naïve insulin T2DM Malaysian patients using the modeling method.

\section{Methodology Model Overview}

The study was conducted using two-stage modeling. The UKPDS outcome model version 2.0 (UKPDS-OM2) was used to estimate the lifetime health benefits of T2DM patients, as well as the long-term patient costs for diabetesrelated complications. A separate model was used to estimate the costs and benefits generated from hypoglycemia because UKPDS-OM2 is unable to measure the impact of hypoglycemia. The UKPDS-OM2 was described in detail by Clarke et al, and the updates of the model were described in Haye et al. ${ }^{13,14}$

The second model was programmed separately in Microsoft Excel ${ }^{\circledR}$ to evaluate the hypoglycemia risk and economic outcome associated with the use of LAIA and NPH insulin in insulin naïve T2DM patients over an annual steady-state time horizon (Figure 1). The model estimated the total costs associated with insulin use, and hypoglycemia and the estimated change in quality-of-life. 
$\Delta$ Cost

Healthcare costs

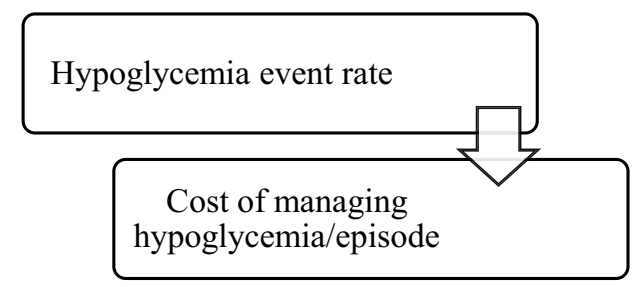

$\Delta$ cost $=$ cost of managing hypoglycemia LAIA- $^{-}$ cost of managing hypoglycemia $\mathrm{NPH}$ insulin
$\Delta$ Effect

Health-related Quality-of-life

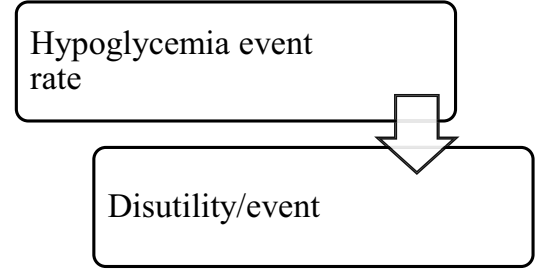

$\Delta \mathrm{QALY}=\mathrm{QALY}_{\text {LAIA }}-\mathrm{QALY} \mathrm{NPH}_{\mathrm{Ninulin}}$

Figure I A simple cost and consequences mathematic model approach to evaluate the reduced hypoglycemia in T2DM treated with LAIA or NPH insulin. The cost of managing hypoglycemia for LAIA= Total number of hypoglycemia event rate $\times$ Total cost of managing hypoglycemia per episode. The cost of managing hypoglycemia for NPH insulin= Total number of hypoglycemia event rate $\times$ Total cost of managing hypoglycemia per episode. Total QALY for LAIA= Total hypoglycemia event/year $\times$ disutility event per episode. Total QALY for NPH= Total hypoglycemia event/year $\times$ disutility event per episode.

Abbreviations: $\Delta$ cost, change in cost; $\triangle$ QALY, change in quality-adjusted life year; QALY, quality-adjusted life year; LAIA, long-acting insulin analogue; NPH Insulin, neutral protamine Hagedorn insulin; T2DM, type 2 diabetes mellitus.

The model simulated the cohort for three different groups (oral hypoglycemic agents (OHAs) with NPH insulin, OHAs with insulin Detemir and OHAs with insulin Glargine). At the beginning of each time period, the model will check for specific fatal or non-fatal events randomly. ${ }^{13,14}$ All the related costs, life-years and qualityadjusted life-years (QALYs) will be calculated when a fatal event occurs, and the simulation will be stopped. $^{13,14}$ The process of simulation begins again annually if the subject does not die in the previous year. The simulation started by checking for events and updating a simulated subject's disease state and applying any appropriate decrement in health utility followed by calculated associated costs. ${ }^{13,14}$ The simulation time clock will stop when all individuals have been simulated. ${ }^{14}$

The sum of the total cost generated from the UKPDSOM2, and the simple model, yields the total healthcare cost for LAIA and NPH (Equation 1). The total cost per patient-generated from the UKPDS-OM2 included the total pharmacy cost and the total cost of managing diabetes-related complications. The second model only generated the total cost of managing severe hypoglycemia per patient. The total cost for each arm was calculated by summing the yearly total healthcare cost (Equation 2) over the specified time horizon.

Equation 1: Total healthcare cost $/$ year $=\sum$ pharmacy cost $+\sum$ diabetes related complication management cost + $\sum$ hypoglycemia cost management cost

Equation 2: Total healthcare cost for 40 -years time horizon/alive patient

\section{Patient Population and Treatment Inputs}

Patient characteristics and risk factors were extracted from the Malaysia Diabetes Registry database (Table 1). The reduction of HbA1c after initiating NPH insulin was $0.84 \% .{ }^{15}$ An additional $0.05 \%$ of reduction of HbAlc in the insulin Glargine arm compared with the NPH insulin was used in the base-case due to a few studies including systematic review reported a positive mean weighted difference in the $\mathrm{HbAlc}$ level between insulin Glargine and NPH insulin. ${ }^{16-19}$ No differences in $\mathrm{HbAlc}$ between insulin Glargine and NPH insulin was used in the sensitivity analysis because Malaysian health technology assessment reported that $\mathrm{HbAlc}$ reduction between insulin Glargine and NPH insulin in the T2DM patients in the two treatment group was not statistically significant after pooled analysis of the related studies. ${ }^{20}$ The HbAlc reduction compared between insulin Detemir and NPH insulin was significant $^{20}$ and the MWD of HbAlc for insulin Detemir versus NPH insulin, between $0.13 \%$ (used in base-case) and $0.07 \%$ (used in the sensitivity analysis). ${ }^{18,19,21-23}$ The HbA1c level dropped after the insulin regimen was introduced and the effect would be maintained for 2 years but increased again at the same rate of $0.1 \%$ per year in all treatment arms and, followed the trend observed in the UKPDS trial. ${ }^{24}$

A meta-analysis reported that the pooled mean net change for patients on insulin Glargine was reported to have gained 0.33 kilograms $(\mathrm{kg})$, which was less weight compared to the $\mathrm{NPH}$ treatment group after six pooled clinical trial studies. ${ }^{17}$ 
Table I Characteristics and Complications of Simulated Cohort

\begin{tabular}{|l|l|}
\hline Variables & $\begin{array}{l}\text { Type 2 } \\
\text { Diabetes (in } \\
\text { Average) }\end{array}$ \\
\hline Patient demographics & \\
Age now (years) mean, median, standard deviation & $62,62, \mathrm{II}$ \\
Gender (\% male) & 36 \\
Duration of diabetes & 8 \\
\hline Baseline risk factor & \\
Weight, male; female (kg) & $74 ; 66$ \\
Height, male; female (m) & $1.64 ;$ I.53 \\
Hemoglobin bAIc (HbAlc) (\%) & 8.2 \\
High-density lipoprotein (HDL)-cholesterol (mmol/l) & 1.3 \\
Low-density lipoprotein (LDL)-cholesterol (mmol/l) & 3.1 \\
Systolic Blood Pressure (mmHg) & 136 \\
Heart rate (bpm) & 75 \\
White blood cell (xI0^9/l) & 7 \\
Haemoglobin (g/dl) & 13 \\
Estimated Glomerular Filtration Rate (eGFR) (mL/ & 80.7 \\
min/l.73m^2) & \\
\hline Baseline macrovascular complications (in & \\
percentage) & 0 \\
Myocardial infarction & 3.6 \\
Ischemic heart disease & 0 \\
Stroke* & 0 \\
Heart failure* & 0.004 \\
Baseline microvascular complications (in percentage) & \\
Renal failure* & 0 \\
Blindness* & \\
Amputation & \\
Foot Ulcer & \\
\hline Not & \\
\hline
\end{tabular}

Note: *The complication was not recorded in the Malaysia diabetes registry database and it assumed that no pre-existing event for the complication.

A clinical randomized trial study reported that compared with NPH insulin, patients treated with insulin Detemir had significantly less weight gain with a difference of $1.5 \mathrm{~kg}$ after baseline-adjusted. $^{22}$ The rates of hypoglycemia (defined as an episode of hypoglycemia that required assistance) for insulin Glargine compared with NPH insulin was expressed as events/patient-year in Table $2{ }^{25}$ The rates of symptomatic hypoglycemia between insulin Detemir and NPH insulin were retrieved from a multi-centre, parallel-group, 24-week clinical trial study in ten European countries. ${ }^{26}$

\section{Estimated Costs}

The analysis was undertaken from the perspective of a third-party payer. Therefore, only health care costs were used in the model (Table 3). The costs of diabetesrelated complications were obtained from a local cost estimation study. ${ }^{27}$ The cost of managing a hypoglycemia event was taken from a local study carried out at Universiti Kebangsaan Malaysia Medical Centre. ${ }^{28}$ The management cost of hypoglycemia increased with each level of severity. It is estimated that the cost of managing a severe hypoglycemia case was MYR $8250 .{ }^{28}$

The acquisition costs (obtained from a Malaysia's public hospital 2015-year purchase price) for the insulins were calculated from prices according to pack size. The price for NPH insulin $\left(\right.$ Novapen $^{\circledR}$ ) is RM 5.13 (US\$ 1.22) per cartridge, insulin Glargine (Lantus ${ }^{\mathbb{B}}$ ) is RM 34.81 (US\$ 8.27) per cartridge and insulin Detemir (Levemir FlexTouch $^{\circledR}$ ) is RM 36.58 (US\$ 8.70) per cartridge. Dosages of NPH insulin, insulin Glargine and insulin Detemir were standardized at 10 units/use as per suggested insulin basal dose for insulin naïve T2DM patients. ${ }^{29}$ The total dose was $36.50 \mathrm{IU} / \mathrm{year}$ for insulin Glargine, Detemir and NPH insulin respectively. It was assumed that a total of $730 \mathrm{IU} /$ year (2 IU/injection) was used for priming the pen before each injection and that 15 cartridges were required for a year. The additional required cost per year for oral medication management of T2DM was RM522.15 (US\$ 124.11) and RM548.70 (US\$ 130.43) per patient for insulin Glargine

Table 2 Therapy Setting for Base-Case Analysis Based on HbAlc Reductions, Changes in Body Weight and Severe Hypoglycemia Between Insulin Glargine and Insulin Detemir versus NPH Insulin

\begin{tabular}{|l|l|l|l|}
\hline & NPH Insulin & Insulin Glargine & Insulin Detemir \\
\hline HbAlc at start of simulation (\%) & $>6.5$ & $>6.5$ & $>6.5$ \\
Stayed on baseline HbAIc (years) & 0 & 0 & 0 \\
$\Delta$ HbAlc reduction compared to NPH (\%) & & -0.05 & -0.13 \\
HbAlc decreased from baseline (\%) & -0.84 & -0.89 & -0.97 \\
Stayed on achieved HbAlc (years) & 2 & 2 & 2 \\
Increase per year \% (rate) & 0.1 & 0.1 & 0.1 \\
$\Delta$ Body weight compared to NPH insulin (kg) & - & 0.33 & 1.5 \\
Severe hypoglycemia (episodes/patient-year) vs NPH insulin & & 0.04 vs 0.065 & 0.01 vs 0.08 \\
\hline
\end{tabular}

Abbreviations: $\Delta$, change in; HbAlc, hemoglobin Alc; NPH insulin, neutral protamine Hagedorn insulin. 
Table 3 Cost of T2DM Complications in the Event Year and Subsequent Year (Annual per Patient Costs)

\begin{tabular}{|l|l|l|}
\hline T2DM Complications & $\begin{array}{l}\text { Event Year, } \\
\text { MYR (US\$) }\end{array}$ & $\begin{array}{l}\text { Subsequent } \\
\text { Year, MYR (US\$) }\end{array}$ \\
\hline Myocardial infarction & $19,381(14,724)$ & $1802(1369)$ \\
Stroke & $8741(6641)$ & $1388(1054)$ \\
Heart failure & $5033(3824)$ & $2246(1706)$ \\
Ischemic heart disease & $3788(2878)$ & $1802(1369)$ \\
Amputation & $5960(4528)$ & $0(0)$ \\
Blindness & $2387(1813)$ & $0(0)$ \\
Renal failure with hemodialysis & $42,395(32,208)$ & $39,522(30,025)$ \\
Diabetic foot ulcer & $316(240)$ & $0(0)$ \\
\hline
\end{tabular}

Abbreviations: T2DM, type 2 diabetes mellitus; MYR, Malaysian ringgit.

and insulin Detemir respectively; and RM 76.98 (US\$ 18.30) for NPH insulin. The costs of self-monitoring blood glucose strips were excluded from the analysis because they were considered to be the patient's own out-of-pocket cost. All patients were assumed to have remained on the same treatment regimen for life, and it was also assumed that all other costs were equivalent in each treatment group.

All costs (drug acquisition costs, and diabetes-related complication management costs and cost of managing severe hypoglycemia) were calculated in Ringgit Malaysia (RM) for the year 2015. The CCEMG-EPPICentre Cost converter was used to convert all currency to 2019 USD. The tool inflated the original price to the 2019 value using the Gross Domestic Product deflator (GDPD) index and converted it to USD based on the Purchasing Power Parities (PPP) for the GDP.

\section{Discounting and Time Horizon}

The incremental cost-effectiveness analysis of LAIA versus insulin NPH covered treatment periods of T2DM patients for more than one year. It was necessary to include the effect of discounting to give future costs and health benefits less weight in the economic evaluation analysis. ${ }^{30}$ An annual discount rate of $3 \%$ was applied to both costs and outcomes. ${ }^{30}$ The time horizon was set at 40 years in the base case analysis in order to capture both mortality and the incidence of diabetes-related complications that might occur over the patients' lifetimes.

\section{Health-Related Utility}

QALY was incorporated into the analysis using diabetesrelated health state utility and event dis-utility from international literature due to lack of local data. The utility values used in the base-case were the default value provided by UKPDS-OM2 (Table 4). These default values are based on the updated estimates derived from UKPS patients and published in 2014 while renal failure and for ulcer are taken from a meta-analysis of quality of life studies. ${ }^{31,32}$ The dis-utility value for the event year was applied in the model for one cycle and the disutility value for subsequent year was applied in the model after the event year and the utility value will remain with the patient until the end of the simulation. For instance, utility value for a patient with heart failure in the event year and the subsequent year was $0.70(0.807-0.101)$ and 0.70 (0.807-0.101) respectively. The dis-utility value for hypoglycemia was retrieved from a local cross-section study. ${ }^{33}$

\section{Statistical Methodology}

A group of 2000 patients was randomly selected for simulation by repeating 10,000 times (loops) for each simulation, and mean values and standard deviations were generated using a non-parametric bootstrapping approach.

\section{Sensitivity Analysis}

Several one-way sensitivity analyses were carried out to assess the effects of varying key model parameters on final

Table 4 Utility Decrements for the Diabetes-Related Complications

\begin{tabular}{|l|l|l|}
\hline Utility or Dis-Utility & First Year or per Event & Subsequent Years \\
\hline T2DM without complication (utility) & 0.807 & \\
Ischemic heart disease (disutility per event) & 0.000 & 0 \\
Myocardial infarction (disutility per event) & -0.065 & 0 \\
Heart failure (disutility per event) & -0.101 & -0.101 \\
Stroke (disutility per event) & -0.165 & -0.165 \\
Renal failure with dialysis (disutility per event) & -0.330 & -0.330 \\
Blindness or severe vision loss, event year (disutility per event) & 0.000 & 0 \\
Active ulcer (infected) (disutility per event) & -0.210 & -0.210 \\
Amputation, event year (disutility per event) & -0.172 & -0.172 \\
\hline
\end{tabular}

Abbreviation: T2DM, type 2 diabetes mellitus. 
outcomes. To explore uncertainty around the cost data collected by primary research, two analyses were performed where the complication and management costs were increased and decreased by $20 \%$ respectively. The lower value of $\mathrm{HbAlc}$ reduction and utilities were applied to assess the impact of the analysis. Deterministic sensitivity analysis was also conducted on discount rates $(0 \%$ and 5\%), and the model time horizon (10, 20 and 30 years) to verify the robustness of the data. Sensitivity analysis was also conducted to assess the impact of insulin dose.

\section{Results}

The findings were that there was an improvement in QALY (between +0.1317 (insulin Glargine) and +0.8567 (insulin Detemir)) in patients with LAIA compared with NPH insulin. Kaplan-Meier (KP) event-free survival rate for diabetes-related complications especially macrovascular complications was higher for patients with LAIA compared to those with NPH insulin. The KP event-free survival rate for cardiovascular death was at least 0.0025 higher for the patient with LAIA compared to those with $\mathrm{NPH}$ insulin. The highest difference of KP event-free survival rate between LAIA and NPH insulin was for heart failure (0.0053) and the lowest difference of KP event-free survival was for all death (0.0003).

Table 5 summarizes the findings after combining the outputs from both models. Insulin Detemir was a dominant option and insulin Glargine was a cost-effective treatment option. The total cost for using NPH insulin, insulin Detemir and insulin Glargine was RM 33,182 (US\$ 7887), RM 39,209 (US\$9320) and RM 38,051 (US\$ 9045) respectively. Even though LAIA has higher therapy cost compared to NPH insulin, the cost may be offset by the total cost of diabetes-related complications and the cost of managing severe hypoglycemia.
The series of sensitivity analyses revealed that the ICER was sensitive to the changes in the acquisition price for LAIA, the discount rate, and the insulin dose (Table 6). It found insulin Glargine was not a costeffective option compared to NPH insulin when the dose exceeded 12 IU. Insulin Glargine was a dominant option when the annual discount rate increased to $5 \%$ or the acquisition cost per year reduced from RM 445 (US\$ 106) to RM 223 (US\$ 53).

\section{Discussion}

Three types of LAIA are available in the Malaysian market. ${ }^{34}$ They are insulin Glargine, insulin Detemir and insulin Degludec. ${ }^{34}$ The perspective of the study was the third-party payer, so, insulin Glargine and Detemir were used as an intervention. Insulin Glargine and Detemir are in the formulary drug of the Ministry of Health ${ }^{35}$ and this means they are reimbursed and available in Malaysia's public healthcare.

The results indicate that either insulin Glargine or insulin Detemir was associated with an increase in QALY compared to NPH insulin in patients with T2DM who did not achieve adequate control with oral antidiabetic agents. Furthermore, LAIA reduced the cumulative incidence of diabetes-related complications and severe hypoglycemia compared to NPH insulin. The results projected that treatment with LAIA requires a higher treatment cost per patient over a 40-year time horizon compared to NPH insulin but this can be offset when considering the total cost of managing diabetes-related complications and the total cost of managing severe hypoglycemia. Consequently, the ICER for insulin Detemir and insulin Glargine over NPH insulin remained well within the threshold for treatments that were regarded as the dominant and cost-effective option respectively.

Table 5 Summary of the Results for Both Insulin Glargine and Detemir versus NPH Insulin

\begin{tabular}{|l|l|l|}
\hline & Insulin Glargine vs NPH Insulin & Insulin Detemir vs NPH Insulin \\
\hline Difference total cost from UKPDS-OM2, MYR (US\$) & $4867(3698)$ & $6026(4578)$ \\
Difference total cost for hypoglycemia, MYR (US\$) & $-4377(3325)$ & $-12,753(9689)$ \\
Total cost, MYR (US\$) & $492(374)$ & $-6727(6727)$ \\
Difference total QALY gained from diabetes related-complication & 0.0115 & 0.0191 \\
Difference total QALY gained from hypoglycemia event & 0.1202 & 0.8376 \\
Total additional QALY gained & 0.1317 & 0.8567 \\
Incremental cost-effectiveness ratio, MYR/QALY (US\$/QALY) & $3732(2835)$ & Dominant \\
\hline
\end{tabular}

Abbreviations: UKPDS-OM2, UKPDS-Outcome Model 2; NPH insulin, neutral protamine Hagedorn insulin; QALY, quality-adjusted life year; MYR, Malaysian ringgit; US\$, United States dollar. 
Table 6 Results of Sensitivity Analysis

\begin{tabular}{|c|c|c|}
\hline \multirow[t]{2}{*}{ Scenario } & \multicolumn{2}{|c|}{$\begin{array}{l}\text { Incremental Cost-Effectiveness Ratio, MYR/QALY } \\
\text { (US\$/QALY) }\end{array}$} \\
\hline & $\begin{array}{l}\text { Insulin Detemir vs NPH } \\
\text { Insulin }\end{array}$ & $\begin{array}{l}\text { Insulin Glargine vs NPH } \\
\text { Insulin }\end{array}$ \\
\hline $0 \%$ discount rate & Dominant & $17,372(13,198)$ \\
\hline $5 \%$ discount rate & Dominant & Dominant \\
\hline I0-year time horizon & Dominant & $25,966(19,727)$ \\
\hline 20-year time horizon & Dominant & $17,179(|0,035|)$ \\
\hline 30-year time horizon & Dominant & $9977(7580)$ \\
\hline Disutility value retrieved from literature review & Dominant & $3733(2836)$ \\
\hline $50 \%$ reduction of the acquisition cost of insulin Detemir and insulin Glargine & Dominant & Dominant \\
\hline The HbAlc reduction for insulin Glargine and NPH insulin are same & & $3950(3001)$ \\
\hline $\mathrm{HbAlc}$ reduction for insulin Detemir was $0.1 \%$ addition compared to $\mathrm{NPH}$ insulin & Dominant & \\
\hline Hypoglycemia rate for LAIA increased $50 \%$ & Dominant & $140,619(106,830)$ \\
\hline Dose increase to $12 \mathrm{IU}$ & Dominant & $26,395(20,053)$ \\
\hline Dose increase to $14 \mathrm{IU}$ & Dominant & $32,362(24,586)$ \\
\hline Dose increase to $28 \mathrm{IU}$ & $307 \mid(2333)$ & $77,113(58,584)$ \\
\hline Cost of managing hypoglycemia reduced $50 \%$ & $14,477(10,998)$ & $53,573(40,700)$ \\
\hline
\end{tabular}

Abbreviations: HbAIc, hemoglobin Alc; NPH insulin, neutral protamine Hagedorn insulin; QALY, quality-adjusted life year; MYR, Malaysian ringgit; US\$, United States dollar; IU, international unit.

The initial objective of UKPDS was to determine the effect of intensive glycemia control on the incidence of complication and the study design was similar to the randomized clinical trial. ${ }^{36}$ Even though the sample might be homogenous, the equation was built from larger data (3642 patients) with a median follow-up period of 10.3 years. ${ }^{13}$ The UKPDS-OM2 updated and re-estimated the risk equation for diabetes-related complications and added new risk equations for diabetes ulcers, all-cause mortality and some second events. ${ }^{14}$ These risk equations were developed based on the continuing follow-up of the patients when they are no longer in a clinical trial. ${ }^{14}$ It means the UKPDS-OM2's risk equations are more similar to the "real world". In UKPDS-OM2, the patient heterogeneity is reflected in the patient-level simulation which means each individual has a unique set of risk factors for the estimation of their probability of events. ${ }^{14}$ Therefore, UKPDS-OM2 may be more suitable to simulate the outcome in this study because the characteristics of the patient may be heterogeneity due to the data were retrieved from the National Diabetes Registry Malaysia. Besides, UKPDS-OM2 allows the decision-makers to understand the benefits of using LAIA without consideration of the hypoglycemia events. The analysis showed an incremental cost per QALY of RM 422,363 (insulin Glargine) and RM 351,319 (insulin Detemir), which is above the acceptable Malaysian threshold of RM 29,080/ QALY $^{37}$ when the analysis only accounted for the cost of managing diabetes-related complications. The high acquisition of LAIA unable to offset by the cost of managing diabetes-related complications. The hypoglycemia model allows the decision makers to understand the impact of avoidance hypoglycemia can reduce the burden in the cost of managing the complication. It also shows how important the hypoglycemia influence the ICER value as the value changed from exceeded threshold to within the threshold.

The findings are consistent with other international studies. $^{24,38-42}$ The literature showed the additional QALY gained from insulin Glargine versus NPH insulin was between $0.008^{43}$ and $0.488 .^{39}$ The total additional QALY gained $(+0.1317)$ in the study was within range and the findings were very similar to a study conducted in the United Kingdom $(+0.111){ }^{41}$ The total additional QALY gained for insulin Detemir versus NPH insulin was 0.8567 . A literature review showed that the range of additional QALY gained was between $0.01^{44}$ and $0.464 .^{45}$ The result exceeded the range. The disutility value of severe hypoglycemia was the main reason that higher additional QALY was gained, with one episode of nocturnal and daytime severe hypoglycemia providing a disutility of 0.2801 and 0.1938 respectively. The 
disutility for severe hypoglycemia was $0.0012 .{ }^{40,45}$ When the severe hypoglycemia disutility was replaced by 0.0012, the additional QALY gained over a 40-year time horizon became 0.3229 which was consistent with other studies in the literature review.

Projected outcomes were most sensitive to changes in the dose of basal insulin especially insulin Glargine. The findings were that insulin Glargine was not a cost-effective option when the incremental dose exceeded 12 IU. However, insulin Detemir remained as a cost-effective option quarterly, even when the basal insulin dose increased to the optimum basal dose $(0.4 \mathrm{IU} / \mathrm{kg} /$ day $)$ because the dose increments directly increased the total pharmacy cost. The high acquisition drug cost especially for insulin Glargine cannot be offset even after accounting for the cost of managing hypoglycemia and diabetesrelated complications. The outcomes for insulin Glargine versus NPH insulin were also sensitive to the changes in annual discount rates because the ICER value changed from being a cost-effective option to becoming the dominant option. This may be because the dollar values aggregated across the time horizon were higher $(2 \%)$ when compared to the standard annual discount rate.

The outcomes were also sensitive to the severe hypoglycemia event rate. When the hypoglycemia event rate reduced $50 \%$, insulin Glargine became not cost-effective (exceeded the cost-effectiveness threshold). The definition of severe hypoglycemia in the study was an episode of the event that required medical assistance which also used to elicit the preference of health state of hypoglycemia event. $^{33,46}$ The event may occur after a brief period of feeling shaky, dizzy, sweaty, irritable or confused and sometimes the patient may experience seizures, convulsions, further confusion, fainting, or fall into a coma. The cost of managing hypoglycemia was high because the event may be required more resources to manage hypoglycemia. This was shown in the sensitivity analysis that insulin Detemir and insulin Glargine switched to cost-effective and no longer cost-effective respectively. The high acquisition drug cost of LAIA in Malaysia was a contributing factor because the cost of LAIA was almost five-fold compared to the NPH insulin. Even though LAIA has a lower total cost in the management of diabetes-related complications compared to NPH insulin, the total therapy cost of using LAIA cannot be offset. The rate of avoiding a severe hypoglycemia event affected the ICER values especially in the case of insulin Glargine. It found that insulin Glargine was no longer a cost-effective option compared to NPH insulin when the avoidance of severe hypoglycemia reduced by $50 \%$. This emphasized the importance of the rate of avoiding severe hypoglycemia between LAIA and NPH insulin, because the ICER value may no longer be a costeffective option. This study had several significant strengths. First, the analysis used country-specific data for healthcare cost and patient epidemiology characteristics. This reflected the actual clinical practice and baseline characteristics of T2DM in Malaysia. The average age of the simulation was 62 years old and it was believed that the time horizon (40-years) was able to capture all the consequences of diabetes' complications because the average life expectancy in Malaysia was 75 years old. ${ }^{47}$ Second, the study followed the processes recommended by the Malaysian pharmacoeconomic guideline.$^{30}$ However, the approach to assessing the costeffectiveness of LAIA versus NPH was limited by a variety of factors. First, the clinical efficacy of the analysis of hypoglycemia was limited to severe hypoglycemia events that required hospitalization. Therefore, this analysis may have underestimated the cost-effectiveness of LAIA being beneficial to moderate hypoglycemia that could only be handled in an outpatient setting or emergency. The use of utility data in the model to obtain the QALY was retrieved from literature and data published overseas, which may have been influenced by different cultural practices ${ }^{48}$ as it influenced the way respondents processed information and made decisions on valuation tasks. $^{49}$

Some limitations should be taken into consideration such as the use of utility data from overseas published literature data to obtain the QALY, which may be influenced by different cultural practices ${ }^{48}$ as it influences the way respondents process information and make decisions in valuation tasks. ${ }^{49} \mathrm{~A}$ retrospective, observational study found the incidence of community-acquired pneumonia with T2DM was $25.8 \%$ and the incidence was higher for all time periods (in 10 years period). ${ }^{50} \mathrm{~T} 2 \mathrm{DM}$ patients have a higher risk of developing infections and sepsis because clinical evidence shows T2DM worsens the prognosis of pathological infections. ${ }^{51}$ The main reason was the homeostasis perturbations in immune cell repletion altered in T2DM patients secondary to over-nutrition and this may be increased adiposity. ${ }^{51}$ However, the UKPDS-OM2 unable to measure or estimate the cost and benefits of preventing pneumonia and septic shock among T2DM. The limitation of UKPDSOM2 being unable to perform probabilistic sensitivity 
analysis. It can be overcome by the bootstrap function in the UKPDS-OM2 that is similar to probability sensitivity analysis because the function can assess the uncertainty surrounding the risk equations, by rerunning the model repeatedly using different risk equations estimated on bootstrapped populations drawn from the original populations. Another limitation of UKPDS-OM2 is the model does not allow other parameter inputs, notably concerning costs and quality of life associated with complications. The acquisition cost and another set of dis-utility values were used in the sensitivity analysis to assess the uncertainty of the input in the cost-effectiveness analysis.

\section{Conclusion}

Insulin Detemir and insulin Glargine are LAIA that can be used as a basal insulin option instead of NPH insulin for the management of diabetes. They provided an enhancement of HbA1c control with a lower level of severe hypoglycemia experienced compared with NPH insulin. The added cost of LAIA therapy should be weighed against future benefits in the form of reduced long-term diabetes-related complications and the reduction rate of severe hypoglycemia. In conclusion, LAIA as a basal insulin regimen for patients with T2DM failing to achieve adequate glycemic control with oral antidiabetic agents alone would be expected to lead to improvements in QALY compared with NPH insulin.

\section{Data Sharing Statement}

The datasets used and analyzed in the study are available from the corresponding author on reasonable request.

\section{Ethical Approval}

This study was obtained from the Medical Research and Ethics Committee (MREC), Ministry of Health Malaysia. The registration number is NMRR-17-3295-37,360 (IIR).

\section{Acknowledgments}

We would like to thank the Diabetes Trials Unit, the Oxford Centre for Diabetes, Endocrinology and Metabolism that provide us to use UKPDS-OM2. We would like to thank the Director-General of Health Malaysia for his permission to publish this article.

\section{Author Contributions}

All authors made substantial contributions to conception and design, acquisition of data, or analysis and interpretation of data; took part in drafting the article or revising it critically for important intellectual content; gave final approval of the version to be published; and agree to be accountable for all aspects of the work.

\section{Funding}

This study is not funded by any organization.

\section{Disclosure}

The authors declare that they have no competing interests.

\section{References}

1. Ruxyn T More than a million adults in Malaysia are not even aware they have diabetes. SAYS. 2018.

2. Hussein Z, Taher SW, Gilcharan Singh HK, Chee Siew Swee W. Diabetes care in Malaysia: problems, new models, and solutions. Ann Glob Health. 2015;81(6):851-862. doi:10.1016/j.aogh.2015.12.016

3. UK Prospective Diabetes Study (UKPDS) Group. Intensive blood-glucose control with sulphonylureas or insulin compared with conventional treatment and risk of complications in patients with type 2 diabetes (UKPDS 33). Lancet. 1998;352(9131):837-853. doi:10.1016/S0140-6736(98)07019-6

4. Petznick A. Insulin management of type 2 diabetes mellitus. Am Fam Physician. 2011;84(2):183-190.

5. Buse JB, Bigger JT, Byington RP, et al. Action to Control Cardiovascular Risk in Diabetes (ACCORD) trial: design and methods. Am J Cardiol. 2007;99(12):21i-33i. doi:10.1016/j. amjcard.2007.03.003

6. Rolla A. Pharmacokinetic and pharmacodynamic advantages of insulin analogues and premixed insulin analogues over human insulins: impact on efficacy and safety. Am J Med. 2008;121(6):S9-s19. doi:10.1016/j.amjmed.2008.03.022

7. Bolli GB, Di Marchi RD, Park GD, Pramming S, Koivisto VA. Insulin analogues and their potential in the management of diabetes mellitus. Diabetologia. 1999;42(10):1151-1167. doi:10.1007/s0012 50051286

8. Mavrogiannaki AN, Migdalis IN. Long-acting basal insulin analogs: latest developments and clinical usefulness. Ther Adv Chronic Dis. 2012;3(6):249-257. doi:10.1177/2040622312454158

9. Hasan SS, Clavarino AM, Mamun AA, Kairuz T. A comparative drug utilisation study of the treatment of diabetes in Malaysia and Australia. Australas Med J. 2015;8(6):179-188. doi:10.4066/ AMJ.2015.2330

10. American Diabetes Association. 7. Approaches to glycemic treatment. Diabetes Care. 2015;38(Supplement 1):S41-8. doi:10.233 7/dc15-S010

11. Bethel MA, Feinglos MN. Basal insulin therapy in type 2 diabetes. $J$ Am Board Fam Med. 2005;18(3):199-204. doi:10.3122/jabf m.18.3.199

12. Tan WL, Asahar SF, Harun NL. Insulin therapy refusal among type II diabetes mellitus patients in Kubang Pasu district, Kedah, Malaysia. Singapore Med J. 2015;56(4):224-227. doi:10.11622/smedj.2014170

13. Clarke PM, Gray AM, Briggs A, et al. A model to estimate the lifetime health outcomes of patients with type 2 diabetes: the United Kingdom Prospective Diabetes Study (UKPDS) outcomes model (UKPDS no. 68). Diabetologia. 2004;47(10):1747-1759. doi:10.1007/s00125-004-1527-z

14. Hayes AJ, Leal J, Gray AM, Holman RR, Clarke PM. UKPDS outcomes model 2: a new version of a model to simulate lifetime health outcomes of patients with type 2 diabetes mellitus using data from the 30 year United Kingdom Prospective Diabetes Study: UKPDS 82. Diabetologia. 2013;56(9):1925-1933. doi:10.1007/ s00125-013-2940-y 
15. Fritsche A, Schweitzer MA, Haring HU. Glimepiride combined with morning insulin Glargine, bedtime neutral protamine hagedorn insulin, or bedtime insulin Glargine in patients with type 2 diabetes. A randomized, controlled trial. Ann Intern Med. 2003;138 (12):952-959. doi:10.7326/0003-4819-138-12-200306170-00006

16. Mu P, Lu H, Zhang G, et al. Comparison of fasting capillary glucose variability between insulin glargine and NPH. Diabetes Res Clin Pract. 2011;91(1):e4-e7. doi:10.1016/j.diabres.2010.09.026

17. Bazzano LA, Lee LJ, Shi L, Reynolds K, Jackson JA, Fonseca V. Safety and efficacy of glargine compared with NPH insulin for the treatment of type 2 diabetes: a meta-analysis of randomized controlled trials. Diabet Med. 2008;25(8):924-932. doi:10.1111/j.1464-5491.2008.02517.x

18. Horvath K, Jeitler K, Berghold A, et al. Long-acting insulin analogues versus NPH insulin (human isophane insulin) for type 2 diabetes mellitus. Cochrane Database Syst Rev. 2007;2:Cd005613.

19. Tran K, Barnajee S, Li H, et al. Long-Acting Insulin Analogues for Diabetes Mellitus: Meta-Analysis of Clinical Outcomes and Assessment of Cost-Effectiveness. Ottawa: Canadian Agency for drugs and Technologies in Health; 2007.

20. Sabirin J, Ku Abd Rahim KN. Health technology assessment: insulin analogues. Malaysian Health Technology Assessment Section, 2012.

21. Waugh N, Cummins E, Royle P, et al. Newer agents for blood glucose control in type 2 diabetes: systematic review and economic evaluation. Health Technol Assess (Rockv). 2010;14(36):1-248. doi: $10.3310 /$ hta 14360

22. Fajardo Montanana C, Hernandez Herrero C, Rivas Fernandez M. Less weight gain and hypoglycaemia with once-daily insulin detemir than NPH insulin in intensification of insulin therapy in overweight type 2 diabetes patients: the PREDICTIVE BMI clinical trial. Diabet Med. 2008;25(8):916-923. doi:10.1111/j.1464-5491.2008.02483.x

23. Singh SR, Ahmad F, Lal A, Yu C, Bai Z, Bennett H. Efficacy and safety of insulin analogues for the management of diabetes mellitus: a meta-analysis. Can Med Assoc J. 2009;180(4):385-397. doi:10.1503/ cmaj.081041

24. Brandle M, Azoulay M, Greiner RA. Cost-effectiveness and cost-utility of insulin Glargine compared with NPH insulin based on a 10-year simulation of long-term complications with the diabetes mellitus model in patients with type 2 diabetes in Switzerland. Int $J$ Clin Pharmacol Ther. 2007;45(4):203-220. doi:10.5414/CPP45203

25. Rosenstock J, Fonseca V, Schinzel S, Dain MP, Mullins P, Riddle M. Reduced risk of hypoglycemia with once-daily glargine versus twice-daily NPH and number needed to harm with NPH to demonstrate the risk of one additional hypoglycemic event in type 2 diabetes: evidence from a long-term controlled trial. J Diabetes Complications. 2014;28(5):742-749. doi:10.1016/j.jdiacomp.2014.04.003

26. Hermansen K, Davies M, Derezinski T, Martinez Ravn G, Clauson P, Home P. A 26-week, randomized, parallel, treat-to-target trial comparing insulin Detemir with NPH insulin as add-on therapy to oral glucose-lowering drugs in insulin-naive people with type 2 diabetes. Diabetes Care. 2006;29(6):1269-1274. doi:10.2337/dc05-1365

27. Shafie AA, $\mathrm{Ng} \mathrm{CH}$. Estimating the costs of managing complications of diabetes mellitus in Malaysia. Value Health. 2018;21:S38. doi:10.1016/j.jval.2018.07.286

28. Aljunid SM, Nur A, Ismail A, Aung YN. Estimation of national economic burden of hypoglycaemia among type 2 diabetes mellitus patients in Malaysia. Value Health. 2016;19:A897. doi:10.1016/j. jval.2016.08.209

29. Zanariah H, Foo SH, Lim SC, et al. Practical guide to insulin therapy in type 2 diabetes mellitus. Malaysian Endocrine \& Metabolic Society. 2011.

30. Lee KKC, Bahri S, Talib A, et al. Pharmacoeconomic guideline for Malaysia. Ministry of Health Malaysia. 2012.

31. Alva M, Gray A, Mihaylova B, Clarke P. The effect of diabetes complications on health-related quality of life: the importance of longitudinal data to address patient heterogeneity. Health Econ. 2014;23(4):487-500. doi:10.1002/hec.2930
32. Lung TW, Hayes AJ, Hayen A, Farmer A, Clarke PM. A meta-analysis of health state valuations for people with diabetes: explaining the variation across methods and implications for economic evaluation. Qual Life Res. 2011;20(10):1669-1678. doi:10.1007/s11136-011-9902-y

33. Shafie AA, $\mathrm{Ng} \mathrm{CH}$, Thanimalai S, Haron $\mathrm{N}$, Manocha AB. Estimating the utility value of hypoglycaemia according to severity and frequency using the visual analogue scale (VAS) and time trade-off (TTO) survey. $J$ Diabetes Metab Disord. 2018;17 (2):269-275. doi:10.1007/s40200-018-0369-z

34. Endocrinology M. Diabetes mellitus MIMS endocrinology: MIMS; 2020. [cited Feb 6, 2020]. Available from: https://specialty.mims. com/diabetes $\% 20$ mellitus/treatment.

35. Pharmaceutical Service Programme. Ministry of health medicines formulary 1/2018: pharmaceutical service programme; 2018. [cited September 21, 2018]. Available from: https://www.pharmacy.gov.my/ v2/sites/default/files/document-upload/fukkm-1-2018-full-listportal_0.pdf.

36. King P, Peacock I, Donnelly R. The UK prospective diabetes study (UKPDS): clinical and therapeutic implications for type 2 diabetes. Br J Clin Pharmacol. 1999;48(5):643-648. doi:10.1046/j.13652125.1999.00092.x

37. Lim YW, Shafie AA, Chua GN, Ahmad Hassali MA. Determination of cost-effectiveness threshold for health care interventions in Malaysia. Value Health. 2017;20(8):1131-1138. doi:10.1016/j. jval.2017.04.002

38. Brandle M, Azoulay M, Greiner RA. Cost-effectiveness of insulin Glargine versus NPH insulin for the treatment of type 2 diabetes mellitus, modeling the interaction between hypoglycemia and glycemic control in Switzerland. Int J Clin Pharmacol Ther. 2011;49 (03):217-230. doi:10.5414/CPP49217

39. Permsuwan U, Chaiyakunapruk N, Dilokthornsakul P, Thavorn K, Saokaew S. Long-term cost-effectiveness of insulin Glargine versus neutral protamine hagedorn insulin for type 2 diabetes in Thailand. Appl Health Econ Health Policy. 2016;14(3):281-292. doi:10.1007/ s40258-016-0228-3

40. Tunis SL, Minshall ME, Conner C, et al. Cost-effectiveness of insulin Detemir compared to NPH insulin for type 1 and type 2 diabetes mellitus in the Canadian payer setting: modeling analysis. Curr Med Res Opin. 2009;25(5):1273-1284. doi:10.1185/03007990902869169

41. McEwan P, Poole CD, Tetlow T, Holmes P, Currie CJ. Evaluation of the cost-effectiveness of insulin Glargine versus NPH insulin for the treatment of type 2 diabetes in the UK. Curr Med Res Opin. 2007;23 (sup1):S21-S31. doi:10.1185/030079907X167570

42. Smith-Palmer J, Fajardo-Montañana C, Pollock RF, Ericsson A, Valentine WJ. Long-term cost-effectiveness of insulin Detemir versus NPH insulin in type 2 diabetes in Sweden. J Med Econ. 2012;15 (5):977-986. doi:10.3111/13696998.2012.692340

43. Cameron CG, Bennett HA. Cost-effectiveness of insulin analogues for diabetes mellitus. Can Med Assoc J. 2009;180(4):400-407. doi:10.1503/cmaj.081180

44. Ridderstrale M, Jensen MM, Gjesing RP, Niskanen L. Costeffectiveness of insulin Detemir compared with NPH insulin in people with type 2 diabetes in Denmark, Finland, Norway, and Sweden. J Med Econ. 2013;16(4):468-478. doi:10.3111/ 13696998.2013.768999

45. Valentine WJ, Erny-Albrecht KM, Ray JA, Roze S, Cobden D, Palmer AJ. Therapy conversion to insulin detemir among patients with type 2 diabetes treated with oral agents: a modeling study of cost-effectiveness in the United States. Adv Ther. 2007;24 (2):273-290. doi:10.1007/BF02849895

46. Evans M, Khunti K, Mamdani M, et al. Health-related quality of life associated with daytime and nocturnal hypoglycaemic events: a time trade-off survey in five countries. Health Qual Life Outcomes. 2013;11:90. doi:10.1186/1477-7525-11-90 
47. Press release: abridged life tables, Malaysia, 2016-2018 [press release]. Department of Statistics Malaysia 2018.

48. Zhang P, Brown MB, Bilik D, Ackermann RT, Li R, Herman WH. Health utility scores for people with type 2 diabetes in U.S. Managed care health plans: results from translating research into action for diabetes (TRIAD) Diabetes Care. 2012;35(11):2250-2256. doi:10.2337/dc11-2478

49. Johnson JA, Luo N, Shaw JW, Kind P, Coons SJ. Valuations of EQ-5D health states: are the United States and United Kingdom different? Med Care. 2005;43(3):221-228. doi:10.1097/00005650200503000-00004
50. López-de-Andrés A, de Miguel-díez J, Jiménez-Trujillo I, et al. Hospitalisation with community-acquired pneumonia among patients with type 2 diabetes: an observational population-based study in Spain from 2004 to 2013. BMJ Open. 2017;7(1):e013097. doi:10.1136/bmjopen-2016-013097

51. Frydrych LM, Fattahi F, He K, Ward PA, Delano MJ. Diabetes and sepsis: risk, recurrence, and ruination. Front Endocrinol (Lausanne). 2017;8:271. doi:10.3389/fendo.2017.00271

\section{Publish your work in this journal}

ClinicoEconomics and Outcomes Research is an international, peerreviewed open-access journal focusing on Health Technology Assessment, Pharmacoeconomics and Outcomes Research in the areas of diagnosis, medical devices, and clinical, surgical and pharmacological intervention. The economic impact of health policy and health systems organization also constitute important areas of coverage. The manuscript management system is completely online and includes a very quick and fair peer-review system, which is all easy to use. Visit $\mathrm{http}: / / \mathrm{www}$.dovepress.com/testimonials.php to read real quotes from published authors. 